\title{
Chapter 2: Educating Scientists about Biosecurity: Lessons from Medicine and Business
}

\author{
JUDI STURE
}

When looking at the intersection of ethics and biosecurity, we are generally concerned about how we may highlight ethical issues and solutions as a means of mitigating the risks of biotechnology being used for malign purposes. This chapter sets out to discover what we may learn for this endeavour from attempts to teach and develop ethical practice and awareness in the fields of medicine and business.

These two areas have paid considerable attention to the teaching and development of ethics in practice while also addressing social, professional and national cultures, which is a key factor in the recognition and interpretation of ethical issues. Because these sectors are engaged on a daily basis with two of the most accountable areas of human experience - health and money - they are probably the focus of the highest degree of ethically related litigation and risk of incurred costs around the world. No doubt this is at least part of the reason behind their increased attention to ethics in recent times. However, some situations go far beyond the issue of economics and law, at least in theory and aspiration, and grow out of global concerns that focus on a common, shared humanity and the goal of human safety and security. By reviewing work from these areas, the aim is to present several recommendations as to how bioethics education around issues of biosecurity in the life sciences may be most effectively addressed alongside existing ethics education courses within life-science degree programmes. 


\section{Experiences with Ethics}

It is important to recognise that life scientists already work in an atmosphere of ethical awareness and accountability. However, recent research ${ }^{1}$ in Europe shows that while ethics and biosecurity are a part of some university-based education and training in the life sciences, they are typically only a very small part, often viewed as a 'bolt-on' concept rather than an integral part of the professional identity of the individual scientist. It is against this background that we can make the claim that there is currently insufficient recognition among scientists of the potential risks of the destructive use of life-science research and we should recognise that this may be a significant barrier to addressing this problem.

From my own communications with colleagues teaching ethics and working on the development of ethics approval and monitoring processes in the UK, it appears to be commonly believed among scientists and others working in academia that society's ever-increasing concerns about ethics and responsible research have been adequately, if not too heavily, addressed by the rise in the prevalence of instruments of control or guidance in these areas. Antagonism among researchers in the UK to a perceived increase in ethical-approval processes appears widespread in my experience. Typically, however, this antipathy is generally hidden from public expression. Yet, it is my estimation that there remains substantial resistance to the requirements of ethics accommodation and approval at the grassroots level, and this is probably due, amongst other things, to a failure of those driving the policies to adequately engage with professionals in the various disciplines to explain and situate the issues effectively. In the past two decades codes of practice, ethical policies and standards of ethics have proliferated in professional associations, universities, research laboratories, and in the public and private commercial sectors. But I would argue that these instruments are insufficient to address the growing risks of dual use in the global security arena. The existence of codes of ethics does not preclude the need for effective enhanced education in ethics on dual use and other biosecurity risks, as evidence shows that their existence does not equate to full or even partial compliance with them. ${ }^{2}$

1 Mancini, G. and Revill, J. 2008, Fostering the biosecurity norm: Biosecurity education for the next generation of life scientists, report by the Landau Network-Centro Volta and Bradford Disarmament Research Centre; Dando, M. and Revill, J. 2010, 'Building international educational resources', this volume.

2 Kaptein, M. and Wempe, J. 1998, "Twelve gordian knots when developing an organizational code of ethics', Journal of Business Ethics, vol. 17(8), pp. 853-869; Schwartz, M. 2001, 'The nature of the relationship between corporate codes of ethics and behaviour', Journal of Business Ethics, vol. 32(3), pp. 247-62; Schwartz, M. 2002. 'A code of ethics for corporate code of ethics', Journal of Business Ethics, vol. 41(1-2), pp. 27-43; Schwartz, M. 2004. 'Effective Corporate codes of ethics: Perceptions of code users', Journal of Business Ethics, vol. 55(4), pp. 321-41. 
Most educated people with whom I work and interact in the UK and beyond (including researchers, tutors and students from around the world) operate on the assumption that they already 'know what ethics are' and know how to 'act ethically' in their work. However, when asked to name a few ethical principles, to describe and locate themselves within the framework of any theory of ethics in research, most fall silent. What people really mean is that they know they already have a value-set. The confusion arises because they are typically referring to their private value-set rather than their professional ethical standards. Unsurprisingly, people become defensive when they feel challenged about their ethical principles, but they mistake the challenge for an assault on, or a questioning of, their private values. Resentment against the teaching of ethics to students and professionals is largely a result of the failure of ethicists to explain clearly what it is they are really referring to. Ethics seems to be one of those unusual subject areas in which most people believe they do not need to be educated because they already understand 'it'. Clearly, this is not always the case. I would argue that the current burgeoning of codes and guidelines can actually blind people into thinking that ethical awareness can be reduced to a tick-box activity rather than being an element of professional identity, character and responsibility. It is too often viewed as an added extra, or something to consider in case of audit.

I would make a case that as well as limited engagement with professional ethics in the context of biosecurity within the life sciences, there is insufficient recognition among scientists in general of the role of private ethical values in the personal uptake (the 'buy-in') of professional ethical ideals and views. ${ }^{3}$ We are all shaped by the culturally derived and expressed standards that governed our upbringing but we seem to forget that these varying value-sets may not always align with professionally required or assumed principles. Einstein apparently said that common sense is the collection of prejudices we have acquired by the age of 18, but this tends to be overlooked as we pat ourselves on the back for our educated and objective outlook as scientists. There is arguably too much emphasis and reliance on the notion that scientists are a breed apart from all cultures, shaped by and sharing in a set of values that are neutral, truth-pursuing and non-judgemental, as if being a scientist somehow confers on a consenting individual a new set of cultural values that supersede all those previously held. This is patently nonsensical, and cannot possibly be true unless the education of scientists somehow produces humans who have never been, and are no longer, subject to the forces of human nature, along with prevailing and past cultural pressures.

3 Sture, J. 2010, 'Private morals and public ethics: cultural aspects of ethical development and ethical learning in the scientific context', Paper presented at the 'Promoting Dual-Use Ethics' Workshop, Australian National University, Canberra, 28-29 January 2010. 
Nevertheless, it is surprising how such a view persists and appears to be held dear by scientists themselves around the world in relation to their day-to-day work. In practice, this view is often a confusion between impartiality and neutrality ${ }^{4}$ or, at the very least, an attempt to secure value-free 'safe' knowledge that does not 'tread upon the sensitive ground of politics or ethics' . ${ }^{5}$ To question this sacred truth is seen to challenge the very nature of the scientific endeavour, rather akin to any attempt to question the right to free speech or academic freedom. However, concerns about the destructive use of the life sciences need to be addressed. If this involves challenging some long-held but perhaps mistaken notions, then so be it.

The emergent appreciation of the risks of biosecurity and biotechnology research was highlighted by the United Nations in December 2008 when the Meeting of States Parties to the Biological and Toxin Weapons Convention (BTWC) called for investigation into and development of the education of life scientists and relevant stakeholders. ${ }^{6}$ If concern is being raised at this level, and is supported by a growing body of evidence suggesting that life sciences and the recognition of dual-use risks is not sufficient among practicing scientists, it seems reasonable to consider how we may go about responding. While the antagonism among many professionals to further development of codes of ethics and approval processes remains, I would suggest that we go beyond the route of codes of ethics and practice (which appear to be the commonly followed path of ethics education and monitoring) and further develop existing ethics education frameworks as a means to communicate the potential for ethical approaches to assist professionals in addressing a range of biosecurity challenges. The next section reviews how this might be done by considering lessons from arenas that have studied matters of ethics for some time.

\section{Ethics Education in Medicine and Business}

The most commonly recognised areas in which ethics play a huge part in regulating the behaviour of practitioners are those of medicine and business. My review here of a range of papers from the journal Academic Medicine focuses on ethics education of students in US medical schools in the 1990s and early 2000s. My appraisal of work in the business and management literature focuses on the Journal of Business Ethics. In contrast to the vast amount of literature

4 Lacey, H. 2004, Is science value-free? Values and scientific understanding, London: Routledge.

5 Proctor, R. 1991, Value-free science? Purity and power in modern knowledge, Cambridge: Harvard University Press.

6 United Nations 2008, Report of the meeting of states parties, December 2008, Convention on the Prohibition of the Development, Production and Stockpiling of Bacteriological (Biological) and Toxin Weapons and on their Destruction, Geneva: UN Publications. 
on medical ethics and the training of doctors as distinct subject areas, ethics in the business world tends to be addressed under umbrella concepts such as Corporate Social Responsibility (CSR), although it is commonly recognised as a discrete issue in companies seeking to synchronise ethical standards in widely differing cultural settings. Crucially, the business concept of CSR often transfers ethical responsibility onto the company rather than the individual, providing a contrast with the medical approach that focuses on the individual practitioner. This is useful when considering the possible destructive uses of life-science research as we need to consider not only the role of the individual but also the community or group, whether it be a professional association, some cultural entity or a nation state.

By looking at the education and development of professionals in these contexts, it is possible to find some useful themes that may help us as we move towards enhancing life scientists' ethics skills in settings where otherwise beneficial research may be subverted for malign purposes, by equipping them to build a sustainable capacity in understanding and pass on the baton to subsequent generations. In the following sections I highlight points drawn from these areas that may be of use in supporting the development of ethics education among life scientists as a means to enhance our security.

\section{Theme One: The Hidden and Informal Curriculum}

Ethics education - at least at some level — is already part of many science education programmes, even if it largely fails to address the risks of malign use of research. It is expected that students and professionals hold ethically appropriate and responsible views, but work has shown that competing valuesets and pressures to which they are exposed during education can undermine individuals' ethical standards. What is explicitly taught is not always what is learned.

A key finding among studies in US medical schools was the existence of a 'hidden curriculum' that pervaded education, often to the detriment of ethical behaviour among students and junior doctors. A number of researchers ${ }^{7}$ found that despite the stated commitments of the medical education system to patient well-being, altruism, empathy and caring, another value-set was being promoted tacitly. This promoted detachment, self-interest, objectivity and a business outlook among the students and newly qualified doctors. The two value-sets were in conflict.

7 Hafferty, F. W. and Franks, R. F. 1994, 'The hidden curriculum, ethics teaching, and the structure of medical education', Academic Medicine, vol. 69(11), pp. 861-71; Hundert, E. M., Hafferty, F. W. and Christakis, D. 1996, 'Characteristics of the informal curriculum and trainees' Ethical choices', Academic Medicine, vol. 71(6), pp. 624-33; Hafferty, F. W. 1998, 'Beyond curriculum reform: confronting medicine's hidden curriculum', Academic Medicine, vol. 73(4), pp. 403-7; Coulehan, J. and Williams, P. C. 2001, 'Vanquishing virtue: The impact of medical education', Academic Medicine, vol. 76(6), pp. 598-604. 
Hafferty ${ }^{8}$ concluded that by looking at the 'products' of the medical education system - be they courses, buildings, appointments of faculty, and so on - it was possible to see evidence of the implicit, business-led culture dominating the medical education system through financial values rather than patient-oriented focus. This even extended onto wards, with senior doctors and medical teams requiring students to behave in certain ways in order to 'get on' professionally, concentrating on the needs of the student doctor instead of the patient. Not only did students absorb these implicit values from faculty and senior doctors, but also they passed them on between themselves. Resultant changes in student behaviour comprised an erosion of the ethical 'being a doctor' standards that they had held when they entered medical school. Students reported having to move away from the traditional empathetic and patient-oriented perspective towards a career-building, self-advancing, financially motivated strategy.

In relation to the overall concerns of this volume, this may lead us to consider what messages about ethics in research are being sent out and heard by lifescience students in the laboratory and classroom. When we teach ethics in life sciences we need to beware of tacitly compromising this with career-driving values. It is understandable that financial pressures affect aspects of education but, while recognising this happens, we need to balance the effects by addressing the resulting ethical implications. We also need to consider how we prioritise values in practice as well as in theory, honestly admitting the pressures we are requiring students to respond to in order to progress their careers. The findings of Hafferty ${ }^{9}$ about 'products' of the educational system are applicable to the science education system also. It is not just in the classroom that values are learned, and the 'wrong' standards may be passed on unwittingly.

While US medical schools focused on teaching and developing ethical awareness in a monocultural way (to 'fit' western standards and values), in $1997 \mathrm{Vega}^{10}$ questioned the tendency of US business schools to teach a universal set of ethical standards, claiming that to do so could have a negative effect on the practices of graduates. Her interest was in promoting intercultural business outcomes and she believed that a focus on westernised approaches was self-defeating in the international business world. She suggested that a combination of relevant stakeholder input, deontology, and utilitarianism could be combined with pertinent community norms, and that when applied in practice, the amount of relativism involved in making decisions could be reduced. In the ethical context, this would mean that decisions made would be situationally, culturally and ethically contingent. She proposed an approach of 'common-norming', in

8 Hafferty 1998, op cit.

9 Ibid.

10 Vega, G. 1997, 'Caveat emptor: Ethical chauvinism in the global economy', Journal of Business Ethics, vol. 16, pp. 1353-63. 
which intercultural co-operation, shared designing of programmes, co-working in difficult teams, and a rising above 'parochialism' would allow different value systems to 'provide the continuum for bridging cultural and ethical differences and birthing mutually acceptable hypernorms ${ }^{\prime}{ }^{11}$ Hypernorms were defined as 'fundamental principles of ethical behaviour that guide religious, philosophical and cultural beliefs' ${ }^{12}$ Common-norming was defined as the moderating of one set of ethical and cultural values to meet another value-set at a mutually acceptable midpoint.

Weaver also critiqued US corporate ethical practices. ${ }^{13} \mathrm{He}$ emphasised the need for recognition of cultural and organisational values and traditions in 'other' cultural settings, and showed how ethical processes can be compromised and de-legitimised by culturally careless practices. This would, of course, be a potentially disastrous situation if it were reproduced in current attempts to address dual-use and biosecurity issues. Weaver's work highlights the need not only to recognise intercultural issues but also the practical and hidden 'workings' of organisations themselves in order to achieve shared understanding.

Work by Muijen ${ }^{14}$ and Wines ${ }^{15}$ showed that two commonly taught strategies for business-ethics training - those of compliance and a cultural change - required top-down transformation to assure their uptake by academics and students. Muijen proposed a 'third route' towards sharing cultural narratives through dialogue, focusing on empowerment and the integration (not management) of diversity of values and perspectives. She challenged the notion of CSR and questioned its meaning to differing cultures. Wines concluded that teaching students utilitarian (outcome-based) approaches is insufficient to prepare them for the complex choices that will face them in the real world. He proposed an integration of ethics with other concepts and theories to enhance students' understanding of the social and cultural place of business and ethics. These include ethical psychology, organisational design and behaviour, motivational theory, and courses on how business, society and the law interact, plus sociopolitical theory and the construction of regulatory frameworks. In rapidly advancing settings such as biotechnology, with its potential for harm as well as good, these are important points. What seems obvious to western eyes in concepts such as CSR is not always so clear to other cultures that may take a

\footnotetext{
11 Ibid, p.1361.

12 Ibid, p.1353.

13 Weaver, G. 2001, 'Ethics programs in global businesses: Culture's role in managing ethics', Journal of Business Ethics, vol. 30, pp. 3-16.

14 Muijen, H. 2004, 'Corporate social responsibility starts at university', Journal of Business Ethics, vol. 53, pp. 235-46.

15 Wines, W. 2008, 'Seven pillars of business ethics: Toward a comprehensive framework', Journal of Business Ethics, vol. 79, pp. 483-99.
} 
different approach to business ethics with cultural responsibility. The notion of integrating ethics education with a range of associated subjects echoes the calls made for the promotion of socially holistic ethics in medical schools.

\section{Theme Two: Personal Morals, Professional Ethical Standards and Power Relationships}

Scientists come to their professional education and practice with a fully formed value-set derived from their own cultural background. There is evidence that this pre-existing set of ethical standards may conflict with the professional principles to which they are expected to adhere. The personal moral value-set includes drivers such as social and religious attitudes and beliefs, and these may not accord with the 'value-free' drivers of scientific activities. On the other hand, certain private moral perspectives may enhance the uptake of professional ethical standards.

An example of this is found in work by Vitell and colleagues. ${ }^{16}$ These authors looked at the relationship between religiosity and ethical identity in the individual (they define religiosity as 'the degree to which an individual is a religious person apart from his/her particular religious beliefs and the way that those beliefs are manifested'). ${ }^{17}$ They suggested these factors may impact on ethical decision-making in business and act as antecedents to the process. Whether or not we accept that religions are the source of morality, we can recognise that they prescribe principles and moral codes that can be fundamental in guiding the life of the individual. Those who hold the view that religious belief should have no role in the activities of the scientist will critique much of this. However, one does not need to be religious to recognise the power of shame and guilt as conformity-drivers. This can work to the good and the not so good. The ethics of compliance depend very much on what is being followed. Perhaps the most useful finding from this work is the recognition that religiosity can be a useful tool in understanding the motivations of an individual or group as an antecedent to ethical decision-making. One need not share the religious beliefs of people to appreciate how their views shape their perspective and may influence their behaviour.

In addition to the potential conflicts between personal morals and professional ethics, there is often confusion among professionals as to the nature of 'ethics' in practice. Is it a toolkit with which to tackle difficult challenges in the real world, or something more - perhaps a part of the professional character, or an essential part of professional identity?

16 Vitell, S., Bing, M., Davison, H. K., Ammeter, A., Garner, B. and Novicevic, M. 2009, ‘Religiosity and ethical identity: The mediating role of self-control', Journal of Business Ethics, vol. 88, pp. 601-13.

17 Ibid, p. 602. 
Many professionals arguably never face the potential inconsistencies between their personal ethical values and the professional standards they tacitly uphold because they either do not recognise the conflict or such a variance never arises in their work. I would suggest that 'ethical awareness and practice should be developed as an embedded part of being a [scientist]' (adapted from Hafferty and Franks ${ }^{18}$ ). Evidence from the medical-school context showed that students were unable to operate according to the ethical standards to which they aspired because of the pressures put on them by the system. ${ }^{19}$ It was suggested this resulted from the relatively powerless position of students in the system hierarchy. Feudtner, Christakis and Christakis proposed that more effort should be directed at maintaining ethical standards rather than trying to alter behaviour, and this could be helped by timely, practical guidance from seniors in dealing with difficult cases as they arise. This placed responsibility on students to raise issues, and seniors to respond effectively to them - meaning that seniors needed to be ethically aware and competent too, often learning from juniors.

In the framework of the concerns of this volume, this leads us to consider how experienced tutors, researchers and practising scientists embody their ethical standards in relation to their private views on a daily basis. Are we practising what we preach? Do we facilitate the provision of adequate and appropriate safe space and time in which students, tutors and working scientists can raise, discuss and question ethical situations and dilemmas without sanctions?

The business literature examined for this chapter also reflected on the potential conflict in power relationships when it considered the ethical expectations of parent companies and subsidiaries operating in different cultures. This work focused on the workplace rather than the educational establishment. Thorne and Bartholomew Saunders ${ }^{20}$ showed how cultural values affected ethical reasoning in multinational companies. They concluded that businesses must not ignore cultural variations in ethical perceptions. They suggested that companies should integrate working systems in such a way as to underpin their global corporate goals while still responding to local organisational norms and routines. They proposed that ethics policy-making teams should comprise people reflecting the full cultural diversity of companies' business operations.

\footnotetext{
18 Hafferty and Franks 1994, op cit.

19 Feudtner, C., Christakis, D. A. and Christakis, N. A. 1994, 'Do clinical clerks suffer ethical erosion? Students' perceptions of their ethical environment and personal development', Academic Medicine, vol. 69(8), pp. 670-9.

20 Thorne, L. and Bartholomew Saunders, S. 2002, 'The socio-cultural embeddedness of individuals' ethical reasoning in organizations (cross-cultural ethics)', Journal of Business Ethics, vol. 35, pp. 1-14.
} 
Work by Robertson and Fadil ${ }^{21}$ and Kim and $\mathrm{Kim}^{22}$ illustrated how cultural aspects of belief and behaviour in the business world can influence the formation of ethical standards. Both ethical intensity and an alignment of cultural with ethical values were instrumental in mediating the decisionmaking of individuals in the professional context. Moral intensity ${ }^{23}$ is defined as the variance in peoples' response depending on the intensity of an ethical dilemma, meaning that more effort is usually put into the hard decisions than easier ones. This of course presupposes that the difficulty or seriousness of a situation is recognised effectively in the first instance. Kim and Kim, in their work on Korean public-relations professionals, found that Korean values of social traditionalism were significantly involved in explaining professionals' attitudes to CSR. Because traditional Korean values harmonised with much of the overall CSR conceptual framework, it was much easier to achieve a good uptake of those values in that culture. Therefore, arguably this alignment factor should be incorporated into any attempt to construct a cross-cultural professional-ethics system, particularly in a potential dual-use context. By taking advantage of cultural and professional ethical alignments in particular frameworks, it may be easier to gain a widespread common agreement about a specific ethical situation.

As with work in US medical schools that commented on the lowly status of medical students, research by Secchi ${ }^{24}$ recognised that individuals in companies are typically identified by their status within the hierarchy and the tasks they have to undertake. Secchi also considered other personal characteristics including culture, gender, age and attitudes towards politics, the environment, religion, and so on. His study resulted in the identification of four implications for business ethics and social responsibility in practice that may be translated into other arenas.

He found that everyone is 'ethically aware' as a means to self-advancement and this is enhanced when people regularly engage in the same social channels (workplace). Individuals best develop a sense of the repercussions of their actions when they interact frequently in situations that enable them to build a cognitive picture of the positive outcomes that can benefit them. In relation to the concerns of this volume, this might involve scientists in two scenarios. Firstly, the social channels of the classroom, laboratory, the grant-writing desk and human-resources department, all of which largely dictate the scientist's current and future prospects, status and financial security. Secondly, the social

\footnotetext{
21 Robertson, C. and Fadil, P. 1999, 'Ethical decision making in multinational organizations: A culture-based model', Journal of Business Ethics, vol. 19, pp. 385-92.

22 Kim, Y. and Kim, S.-Y. 2010, 'The Influence of cultural values of perceptions of corporate social responsibility: application of Hofstede's dimensions to Korean public relations practitioners', Journal of Business Ethics, vol. 91, pp. 485-500.

23 Robertson and Fadil 1999, op. cit.

24 Secchi, D. 2009, 'The cognitive side of social responsibility', Journal of Business Ethics, vol. 88, pp. 565-81.
} 
channel of the communal environment as a safe forum in which to discuss potential or real dilemmas and articulate and respond to these with the input and support of peers, instead of feeling isolated, unsure or afraid of the best way to respond in challenging situations. This latter point is visibly lacking in the day-to-day science context.

Further, Secchi found that social responsibility (behaving ethically) serves as a reinforcing mechanism. It works as a shared 'tie' between the giver and receiver (colleagues, end-users, employers, stakeholders) and it is up to the individual to be socially responsible or not. However, as he pointed out, there are difficulties in this scenario. The freedom to choose how to act can be impacted by a range of forces. At the bottom of this is motivation, and it is obvious that individuals can appear to act ethically when in fact they are only doing so for self-serving purposes. The apparently ethical action may not be driven by altruism, philanthropy or some other beneficent force but purely or principally by selfinterest. This makes it impossible to truly interpret the action of the individual, and in this we confront the personnel reliability dilemma. However, unless we allow each scientist the freedom to choose how to act, we are exposing ourselves to the prospect of totalitarian control of the scientific process, which cannot be a viable or desirable way forward. The final finding of interest made by Secchi is the effect of the long-term exploitation of social channels experienced by individuals in groups. This presupposes the availability of shared social channels in which each person can formulate, test and enhance their sense of social responsibility or ethical perspectives in a safe and supportive space.

The life sciences are an area of research that could potentially produce significant malign outcomes for the world's population. This should lead us to consider the need for bodies such as universities and research-science organisations to explicitly recognise the existence of culturally diverse values and norms by enabling and requiring discussion and active focus on them in relation to ethics in science. However, while aiming to encompass a range of cultural perspectives, we should clarify that recognition need not, and should not, necessarily mean validation or result in practical implementation.

While this should not be difficult in view of the present-day emphasis on diversity, in practice, it will probably be challenging because such a process may appear judgmental. In particular, this could be the case when we consider religious pressures and norms, and characteristics such as religiosity. However, I would suggest this is a nettle that needs to be grasped. If a greater understanding of religious ideals and norms as opinion-formers and behaviourdrivers will enhance our understanding of how we make ethical decisions, let's pursue that understanding. There is a need to integrate systems in our universities and scientific organisations to reflect our global ethical goals while still responding to 'local' norms; that is, culturally variant norms. We should 
involve representatives of all cultural stakeholders in decision-making when developing policies as well as deciding what sanctions would result if policy is not put into practice. Social channels can be any concept from the family to the state level, each applying its own pressures to behave in certain ways in order to 'get on'. Crucially, we need to introduce, or develop and support, where existing opportunities are offered, a safe time and space to engage in ethical debate within scientific communities and provide spaces where individuals can formulate, test and enhance their sense of social responsibility or ethical perspectives.

\section{Theme Three: Ethics Training at the Right Time}

Medical-school research shows that it is important to focus ethics education effectively in terms of timing and content. Instead of delivering 'classes on ethics' and testing students on their theory knowledge, it is seemingly more beneficial to stage the delivery and development of ethical awareness throughout the course of a programme.

Work by Christakis and Feudtner ${ }^{25}$ found that traditional medical-school ethics teaching was limited in its effects because it did not focus sufficiently on the needs of students in ways that reflected their stage of training: students were being taught about their ethical responsibilities as doctors but they were still students. They concluded that ethics education for students should be 'resituated within a framework of the student's ethical development ${ }^{26}$ and recognition must be made of the stages of intellectual and emotional development that students pass through during their training and professional life. They also recognised that there should be a place for such changing judgements to be aired and allowed within the hierarchy of the medical team without negative repercussions. It was apparent from their work that the ethical theory or ethical principles approach needed to be augmented with daily decision-making processes and practice, to allow the theoretical to become something like a professional code of conduct. They suggested that a process-oriented model of ethics teaching would allow students to develop their ethical reasoning capabilities both individually and as part of a team.

This study was supported in $1994^{27}$ in an examination of the effects of a single ethics class on a group of first-year medical students. It was concluded that a short course in ethics was unlikely to change students' values or opinions,

\footnotetext{
25 Christakis, D. A. and Feudtner, C. 1993, 'Ethics in a short white coat: the ethical dilemmas that medical students confront', Academic Medicine, vol. 4, pp. 249-54.

26 Ibid, p. 253.

27 Shorr, A. F., Hayes, R. P. and Finnerty, J. F. 1994, 'The effect of a class in medical ethics on first-year medical students', Academic Medicine, vol. 69(12), pp. 998-1000.
} 
citing the varied backgrounds, religious affiliations and personal experiences of classes. This was echoed in the business literature by Wines, ${ }^{28}$ who suggested that there should be a progression of ethics sessions or courses throughout an educational programme, tailored to match the level of ethical decisions that were being faced by students at each time, and topped off with a 'capstone' ethics course to complete the circle.

When considering biosecurity and the protection of life-science research from harmful uses, this may lead us to consider the timing of ethics classes as well as the content. Asking too much too soon of students may be inappropriate. By tailoring ethics teaching to a stage-appropriate set of questions and challenges, students may engage more effectively with both practical and theoretical issues. It seems that it is also as important to provide students with opportunities to develop associated interpersonal skills, as it is to provide them with ethics as a set of knowledge. By providing a longitudinal, stage-specific, culturally and philosophically holistic set of ethics courses and associated sessions and discussion opportunities, we may be able to develop in individuals and groups a greater sense of becoming a ethical practitioner and promoter of social benefit. In addition, it is important to pass on the notion that ethics is not just a set of facts, rules and principles, but a way of being and a part of identity as a professional.

\section{Theme Four: Culturally Holistic Training}

It is has been recognised in both the medical and business literature that it is not only desirable but necessary to incorporate an increased social awareness into educational programmes and professional practice. This is an issue that goes right to the heart of the risks of biotechnology being used for malign purposes. It can be argued that scientists working in research laboratories are to some extent cushioned from exposure to the outside world and the effects of their work. Today, while this may be acceptable as long as effects of the work are beneficial, it is clear that we should highlight to professionals working in life sciences the need to review their work and its potential outcomes in a wider, culturally holistic sense. It is probable that we can no longer simply carry out research for its own sake and publish freely, as has been largely the case to date. We must consider far more carefully how we work and communicate in the future. This entails consideration of how we view and approach scientific work from the beginning of any project to beyond its laboratory end.

In seeking to minimise risks of dual use this may lead us to consider the bigger picture - a holistic view of where our science sits in the world. Just as medicine 
lies in a range of cultural frameworks, so do the life sciences. It is important to challenge students, tutors and working scientists with an outsider's view of their work. Why are they doing what they do? Who will it help? Who will it hinder? Is it right to pursue what they are doing? Clearly this is already happening in some fields, for example in relation to human reproduction and stem-cell research, but we need to widen this approach to include all life sciences. We should view ethics education as enculturation into professionalism - we need to begin to develop new norms and challenge old ones that hold we may do science because we can do science. Hafferty and Franks ${ }^{29}$ suggested that teaching and learning should operate in a reflective and responsive way as students confront ethical issues, but that ethical issues should be considered in the wider cultural environment in which the medical tradition exists. Their view was that rather than a need for more classes, ethics would be better taught by starting training in it early and continuing throughout the learning process. An 'ethical' (that is, professionally 'moral') view of life science may need to be reinstated - and we need to negotiate the pressures that define those privateinto-professional morals as ethical identity.

From the business side, Wines' ideas ${ }^{30}$ about integrating ethics teaching with that of other concepts are also important. Unless we introduce a range of culturally meaningful theories and ideas to scientists and associated professionals, the notion of ethics will continue to be viewed as a 'bolt-on' to everyday practice. By incorporating a range of subjects into the delivery of ethics education, a holistic perspective will be provided and fostered in those engaged in learning. Wines' focus on the need to enhance ethics teaching as a means to counterbalance the financial drivers promoted and prioritised in education and the idea of ethics 'capstone courses' is one that we ought to seriously consider in the biosecurity and dual-use context.

\section{Theme Five: Ethics as Part of Professional Identity}

The process of enculturation into a concept of professional identity is mentioned in one way or another by a range of authors already cited. This process was described by Swick ${ }^{31}$ in a paper that identified nine characteristics of a doctor that equate to a state of medical professionalism and it would be possible to relate this easily to the life-science scenario. He highlighted the subordination of the physician's (scientist's) own interests to those of others, adherence to high ethical standards, response to societal needs in a social contract, the evincing of core humanistic values (empathy, caring, and so on), self- and

29 Hafferty and Franks 1994, 'op cit.

30 Wines 2008, op. cit.

31 Swick, H. M. 2000, 'Toward a normative definition of medical professionalism', Academic Medicine, vol. 75(6), pp. 612-16. 
group-accountability as doctors (scientists), and reflective practice. These traits could be fostered in existing educational contexts by expanding the scope of ethics to make students aware of their individual role in the ethical behaviour of the wider scientific community. Kenny, Mann and MacLeod, ${ }^{32}$ who developed further the notion of professional character by looking at the use of role models as an educational tool, also supported this. They suggested that attempts to teach students ethics in the tool-kit format led to the ethics of character being lost. In their view, the ethical nature of the agent is central to solving ethical dilemmas, rather than the simple application of a set of principles. They suggest a return to the virtue-ethics nature of medicine as 'virtuous physicians both model good behaviour and comprehend the reasons for their choices' ${ }^{\prime 3}$ and the apprenticeship model reflects centuries of professional education.

Hafferty ${ }^{34}$ identified themes through which ethics education and awareness could be addressed and easily incorporated into the life sciences: organisational policy development, a re-evaluation of all processes from teaching, learning and assessment through academic appointments and organisational practices, resource allocation and prioritisation, and what he referred to as institutional slang (changes in the use of everyday language that reflected the dominant mode of thinking in the medical education system, giving examples of businessspeak, illustrating the changing socio-cultural influences acting on the system). These areas of concern reflected crucial earlier work by Miles et al. ${ }^{35}$ which focused on the need to address four institutional areas in order to successfully embed ethics education in medical schools - support from the dean, support from administrative centres, the development of faculty approaches to ethics, and collegial support of an ethical culture. This top-down approach has been mentioned earlier, and is absolutely pivotal in achieving wide uptake of ethical processes and attitudes.

All of this leads us to consider issues around how scientists view themselves as professionals and as ethical practitioners. We need to enhance awareness of the place of science and scientists in society, encouraging them to look at themselves as engaged actors in a moving social, economic and technological drama. Society arguably demands more accountability today than in previous decades. Given that scientists hold such a key role in the balance between beneficent and maleficent outcomes for the human race, we need to broaden the way we look at our scientific work to encompass a truly holistic social perspective. Just as ethics ought to be a fundamental consideration in all research, so should awareness

32 Kenny, N. P., Mann, K. V. and MacLeod, H. 2003, 'Role modelling in Physicians' Professional Formation: Reconsidering an Essential but Untapped Educational Strategy', Academic Medicine, vol. 78(12), pp. 1203-09.

33 Ibid, p. 1207.

34 Hafferty 1998, op. cit.

35 Miles, S. H., Weiss Lane, L., Bickel, J., Walker, R. M. and Cassel, C. K. 1989, 'Medical ethics education: Coming of age', Academic Medicine, vol. 64(12), pp. 705-14. 
of biosecurity risk be clarified in scientific endeavour at all stages of research. There is also an argument for a return to an individually mediated virtue ethics to counterbalance the purely deontological or teleological approaches. Miles' work $^{36}$ looking at the need for top-down support also balances a virtue-ethics approach; that is, meeting the individual scientist halfway. I would suggest that without high-level engagement with top-down management of ethics - be it at the level of laboratory director, course leader or politician or civil servant operating at state level - any efforts to institute and influence 'coal-face' ethical identity and individuals' values and norms will be diluted or simply not taken up in many areas.

\section{Summary of Good Practice from Medicine and Business}

In the previous sections I have considered research from the medical and business contexts and drawn out some ideas that we may be able to use and develop to prevent the malicious use of biotechnology. By drawing on lessons learned by other professionals, we can now consider a range of recommendations arising from these sources.

Five themes have been highlighted:

- The hidden curriculum that can compromise ethical behaviour

- The clash of personal morals, professional ethical standards and power relationships in which private values conflict with professional principles that are supposed to be value-free

- Ethics training at the right time, to allow for stage-appropriate learning and development; culturally holistic training in which ethical behaviour and values are considered and developed in the context of wider society rather than in the rarefied atmosphere of the laboratory or classroom

- Culturally holistic training, in which scientific activity is carried out in the recognised framework of wider society, with an embedded acknowledgement of the possible affects that could result

- Ethics needs to be part of professional identity, in which students and scientists may be allowed opportunities to develop an ethical character and foster a professional identity that encourages cultural responsibility.

Within these themes we can see many practical and theoretical issues that may offer direct support to the development of dual-use ethics awareness in the life sciences. These include: 
- activities involved in common-norming: a sharing of responsibilities between varying cultures and levels of hierarchy in any given context when planning

- the fundamental recognition of cultural and organisational values and traditions themselves in 'other' cultural settings

- the recognition that certain cultural perspectives align well with ethical ones, but vary considerably

- the necessity of top-down transformation in order to assure uptake by academics, students and professionals

- the presentation of both deontological and teleological ethical theory to students while engaging them with real-life scenarios along with consideration of a virtue-ethics approach

- the idea that more effort should be directed at maintaining ethical standards as they are derived from private moral values rather than in trying to alter behaviour

- the need to provide and support a safe community space in which to allow students and practising scientists to discuss and debate ethical issues safely without fear of personal loss of advancement

- the need to address organisational/institutional areas in order to successfully institutionalise ethics education in the life sciences as it applies to dual use.

These themes and issues have been identified through a relatively short review of the literature in just two areas. Further work will doubtless highlight more useful material on which we can start to build. While it is not a simple cut-tofit exercise in which we can lift lessons learned elsewhere wholesale into the biotechnology-security setting, we can in all probability move forward with these lessons confident that we may avoid some of the pitfalls experienced in medicine and business.

\section{Conclusions}

It is clear that culture plays a major part in the development of our views and beliefs. Even in the substantially monoculture of the US medical school, we can see clashes of cultural values at personal and professional levels; and how much more so do we see these when comparing value-sets from around the world in the business literature?

Some may resist enhancement of ethics education to incorporate dual-use issues and argue that the subject is being overcooked and that we are in danger of 'seeing reds under every bed'. That may be so, and perhaps only time will tell, once we have that great lens of hindsight through which to look back. But I would suggest that even if we do not eventually see as much evidence of 
risk as we think we face from today's perspective, we must recognise that we only need one or two cases of the malicious use of today's otherwise benign biotechnology to potentially cause untold damage to millions of people. When the possible fields in which such dual use can occur are outlined (synthetic biology, nanotechnology, neuroscience, phytopathology, to name but a few), it is surely not difficult to appreciate that an over-perception of risk, if it is such, can be justified, when one considers the potential outcomes if it is not mitigated in some way.

Motivation is a key issue in much of what we have covered above. It is too simplistic to categorise doctors as behaving ethically because of their care for the best interests of the patient and businesses acting from care for their profit margins. Doctors may just as easily be operating ethically to protect themselves from being sued for negligence as for the good of the patient. Likewise, businesses may be acting out of good will to their own employees and their dependants just as much as in the interests of maximising profits. Scientists are faced with similar dilemmas in the life-science setting, when considering how to handle risks. They can act for the greater good, but also have to consider their own career advancement, reputation, safety, and so on, as well as the costbenefit equation for others. The scientific community can be quite closed against maverick thinkers and individuals who wish to plough a new furrow if doing so involves challenging accepted norms within disciplines or science as a whole. As academics, we may like to hold to our cherished 'academic freedom' but in reality we do not possess such a thing - everything is subject to standards and rules received and upheld by the majority to maintain the status quo.

What can medical and business ethics teach tell us about educating scientists regarding biosecurity? I would suggest we could learn a great deal, as is evident here. Perhaps the most important lesson is that we cannot simply apply the values of one culture across the board when we come to look at global issues. Even universal questions have a wide range of answers.

What then can be taken from this analysis for moving forward in relation to the concerns of this volume? I would propose we could make a decision to adopt a new approach, starting with that of a form of common-norming in the first instance, which will allow all of us space, time and an engaged audience with which to introduce, debate and disentangle any subject that may be or become of ethical concern in some way. Secondly we need to provide, as early as possible, safe places and opportunities to debate the issues without fear of repercussion. Alongside these developments we can move forward to work with life scientists to enhance a wider recognition and understanding of dual-use issues more generally. This process will take time and considerable effort on the part of many people and organisations, drawn from many cultural settings, 
but is surely worth pursuing as we aim to enhance existing ethical awareness among life scientists by introducing them to the concept of the dual-use of biotechnology. 